\title{
ANALISIS PENGALAMAN WISATAWAN MELALUI NILAI YANG DIRASAKAN TERHADAP KEPUTUSAN PEMBELIAN PADA MAKANAN LOKAL KOTA SEMARANG
}

\author{
Romi Setiawan, Augusty Tae Ferdinand \\ Magister Manajemen, Fakultas Ekonomika dan Bisnis, Universitas Diponegoro
}

\begin{abstract}
ABSTRAK
Penelitian ini dilakukan berdasarkan dari kesenjangan hasil penelitian terdahulu (research gap) mengenai pengalaman wisatawan terhadap keputusan pembelian produk. Serta menguji secara empiris factor-faktor yang dapat mempengaruhi keputusan pembelian seperti nilai hadiah, nilai nostalgia dan nilai ikonik. Karena keputusan pembelian dipengaruhi dari persepsi nilai yang dirasakan oleh konsumen. Tujuan dari penelitian ini yaitu membangun sebuah model konseptual untuk menggambarkan dan memberikan jawaban pada kesenjangan variable pengalaman wisatawan dan keputusan pembelian melalui nilai hadiah, nilai nostalgia dan nilai ikonik. Penelitian ini dilakukan di Kota Semarang dengan responden yaitu wisatawan yang pernah berkunjung ke kota Semarang dan melakukan pembelian makanan lokal. Jumlah responden yang digunakan yakni sebanyak 160 responden. Teknik analisis yang digunakan adalah Structural Equation Model (SEM) dengan menggunakan AMOS 24. Hasil analisis SEM memenuhi kriteria dari Goodness Of Fit Chi-square 184.579, probabilitas 0.015, GFI sebesar 0.897, TLI sebesar 0.988, CFI sebesar 0.989 CMIN/DF sebesar 1.273 dan RMSEA sebasar 0.41. Hasil pengujian menghasilkan bahwa pengalaman wisatawan berpengaruh positif terhadap nlai hadiah, nilai nostalgia dan ikonik serta nilai nostalgia dan ikonik berpengaruh positif terhadap keputusan pembelian makanan lokal Kota Semarang. Sedangkan nilai hadiah tidak berpengaruh pada keputusan pembelian.
\end{abstract}

Kata Kunci: Pengalaman wisatawan, Nilai Hadiah, Nilai Nostalgia, Nilai Ikonik, Keputusan Pembelian.

\section{PENDAHULUAN}

Pariwisata saat ini menjadi sektor industri yang di fokuskan pemerintah untuk dikembangkan, hal ini karena industri pariwisata mampu untuk memberikan 
pendapatan nasional yang cukup besar, alasan lain adalah karena sektor pariwisata mampu mendorong pertumbuhan pada sektor lain misal (1) meningkatkan pertumbuhan Usaha Kecil Menengah (UKM) lokal sebagai dampak pembangunan pariwisata (2) meningkatkan jumlah industri transportasi dan akomodasi yang berkaitan langsung dengan sektor pariwisata (3) meningkatkan pendapatan pada sektor pertanian dan peternakan lokal pada industri perhotelan (4) mampu mempromosikan dan memperluas pemasaran barang lokal termasuk makanan dan minuman lokal.

Saat ini makanan dijadikan sebagai salah satu elemen yang digunakan sebagai alat pencitraan untuk menarik wisatawan datang ke suatu daerah. Boyne dan Hall dalam Steinmetz (2010) bahwa wisatawan yang datang berkunjung ke suatu daerah menghabiskan anggaran yang mereka gunakan untuk berwisata sebesar 40\% untuk membeli makanan lokal baik untuk dikonsumsi maupun untuk dijadikan souvenir. hal ini didukung oleh penelitian yang dilakukan oleh Ma dan Xu (2016) yang mengatakan bahwa wisatawan akan menjadikan makanan lokal sebagai suvenir dengan karakteristik makanan lokal yang masih orisinal, berkualitas, kemasan dan adanya persepsi nilai etnik daerah yang melekat pada makanan lokal tersebut.

Pada Saat wisatawan memilih makanan lokal yang ingin ia konsumsi dan menjadikan souvenir baik untuk dirinya sendiri maupun rekan-rekannya, maka sangat diperlukan pengalaman dalam memilih produk makanan tradisional, dengan pengalaman yang telah tercipta maka wisatawan mampu untuk melakukan seleksi terhadap makanan lokal yang tersedia sehingga mampu meningkatkan keputusan pembeliannya dan memantapkan dirinya untuk melakukan keputusan pembelian pada produk yang diinginkan.Penelitian tentang pengalaman konsumen apakah berpengaruh terhadap keputusan pembelian seseorang masih menimbulkan pro dan kontra, dimana penelitian yang dilakukan oleh Frambach, Roest et al. (2007), Karimi, Papamichail et al. (2015), Lin and Chen (2006) menunjukkan bahwa pengaruh dari gambaran budaya, pengetahuan tentang produk akan mempengaruhi keputusan pembelian konsumen.

Namun juga terdapat penelitian yang menyatakan bahwa pengalaman konsumen tidak membuat seseorang melakukan keputusan pembelian, seperti pada penelitian yang dilakukan oleh Agata Wawrzyniak, Fatimah Furaiji et al. (2012) dan Mohd Noor, Masuod et al. (2016) yang menyatakan bahwa pengalaman konsumen dalam mengkonsumsi produk tidak mempengaruhi keputusan mereka untuk membeli.

Adanya inkosistensi hasil penelitian terdahulu terkait pengalaman konsumen dan keputusan pembelian membuat peneliti mencoba untuk meneliti tentang pengalaman wisatawan terhadap keputusan pembelian makanan lokal 
menggunakan teori penciptaan nilai, maka dari itu pertanyaan penelitian adalah: apakah pengalaman wisatawan berpengaruh terhadap nilai hadiah dan keputusan pembelian, apakah pengalaman wisatawan berpengaruh terhadap nilai nostalgia dan keputusan pembelian, Apakah nilai ikonik berpengaruh terhadap nilai nostalgia dan keputusan pembelian, Apakah pengalaman wisatwaan berpengaruh terhadap nilai ikonik dan keputusan pembelian. Dari pertanyaan penelitian di atas, tujuan dari penelitian ini adalah: (1) Menganalisis dan pengaruh pengalaman wisatawan terhadap nilai hadiah; (2) Menganalisis pengaruh pengalaman wisatawan terhadap nilai nostalgia; (3) Menganalisis pengaruh pengalaman wisatawan terhadap nilai ikonik; (4) Menganalisis pengaruh nilai ikonik terhadap nilai nostalgia; (5) Menganalisis pengaruh nilai hadiah terhadap keputusan pembelian; (6) Menganalisis pengaruh nilai nostalgia terhadap keputusan pembelian; (7) Menganalisis pengaruh nilai ikonik terhadap keputusan pembelian.

\section{TELAAH PUSTAKA}

\section{Pengalaman Konsumen}

Menurut Kwortnik and Ross (2007) pengalaman pada konsumen dapat tercipta dengan menggabungkan atribut yang nyata (indra) dengan yang tidak berwujud (simbolik) yang terbentuk secara bersama-sama oleh konsumen, produk dan pemasar untuk membuat ingatan yang positif didalam diri konsumen. Pengalaman dalam pemasaran dapat dikatakan tercipta apabila konsumen telah melalui tahapan - tahapan seperti pencarian, pembelian, konsumsi dan fase setelah mengkonsumsi sebuah produk (Teixeira, Verma et al. 2012)

Pengalaman konsumen merupakan konsep yang terdiri dari berbagai dimensi yang dapat tercipta pada diri konsumen setelah ia mengkonsumsi suatu produk sehingga memberikan dimensi nilai-nilai indera, emosional, kognitif, perilaku dan relasional yang menggantikan nilai-nilai fungsional (Nasermoadeli, Ling et al. 2013). Pengalaman konsumen juga sering didefinisikan sebagai serangkaian nilainilai emosional yang tercipta pada diri seseorang atas adanya rangsangan yang dirasakan pada saat melakukan konsumsi pada produk atau jasa (Verhoef, Lemon et al. 2009). Secara umum pengalaman konsumen dibagi menjadi 3, sensory experience, emotional experience dan social experience.

\section{Nilai Hadiah}

Menurut Beatty, Kahle et al. (1991) Nilai hadiah (gift giving) didefinisikan sebagai nilai yang mampu memberikan motifasi yang bertujuan menciptakan kepuasan kepada diri sendiri dan kepuasan kepada penerima hadiah dari barang 
yang diberikan, hadiah yang diberi dapat dalam bentuk barang berwujud maupun sesuatu yang tidak berwujud (baik seperti objek atau layanan) dan pengalaman.

hadiah didefinisikan sebagai barang atau layanan yang ditawarkan secara sukarela kepada orang atau kelompok. Membeli hadiah untuk orang lain berbeda dengan melakukan pembelian untuk diri sendiri, pembelian hadiah melibatkan penilaian berdasarkan persepsi dari citra pemberi dan penerima, sifat simbolis, emosi dan motivasi (Zhang and Epley 2011).

\section{Nilai Nostalgia}

Nostalgia merupakan salah satu tipe dari kebutuhan psikologi, nostalgia dapat dedifinisikan sebagai keadaan emosional yang terbentuk ketika seorang individu mengalami interaksi terhadap ingatan akan kejadian dimasa lampau ketika ia mengalami kejadian yang sama. Nostalgia dapat terjadi ketika seseorang merasakan suasana itu sebagai penghubungnya dengan ingatannya pada periode waktu yang berbeda (Yeh, Chen et al. 2012).

Kata nostalgia sering digunakan untuk menggambarkan tentang kenangan emsional yang dialami seseorang terhadap lingkungan dan peristiwa masa lampau yang pernah dialaminya. Dengan kata lain nostalgia diartikan sebagai ingatan seseorang terhadap suatu peristiwa yang mengacu pada fenomena psikologis yang dipicu oleh persepsi obyektif dan objektif (Sedikides, TimWildschut et al. 2008).

\section{Nilai Ikonik}

Nilai ikonik dapat didefinisikan sebagai nilai yang tercipta karena adanya nilai-nilai yang melekat kuat baik dalam bentuk symbol, merek, ataupun tema pada ingatan masyarakat, di negara berkembang nilai ikonik sering juga dikaitkan pada symbol, bentuk, dan tema yang masih berhubungan kuat dengan budaya lokal (Holak 2013).

Menurut Kravets and Örge (2010) nilai ikonik adalah sebuah symbol yang mampu menghidupkan dan mewakili momen sejarah dari social dan budaya dari suatu daerah. Nilai ikonik mampu memancing keinginantahuan orang untuk mengenal lebih jauh budaya suatu daerah. Dalam memilih suatu produk lokal untuk dikonsumsi Konsumen akan menentukan pilihannya dengan melihat isyarat-isyarat (visual) keaslian pada produk.

\section{Keputusan pembelian}

Menurut Chiew et al (2014) di dalam penelitiannya mengatakan bahwa persepsi seseorang terhadap suatu produk akan berpengaruh terhadap niat membeli mereka dan secara langsung juga mempengaruhi pembelian aktual. Banyak perusahaan yang menggunakan niat membeli sebagai alat untuk 
memprediksi penjualan akan produk mereka yang tawarkan ke masyarakat, hal ini terjadi karena menurut Pelsmacker, Driesen \& Rayp (2016) konsumen yang memiliki niat membeli yang lebih besar akan meningkatkan keputusan pembelian mereka juga sehingga akan cenderung bersedia membayar harga premium pada untuk produk yang sama.

Jika konsumen merasa tertarik dan menginginkan sebuah produk maka ia akan melakukan pembelian pada produk tersebut, dalam mengambil keputusan untuk membeli sangat bergantung pada nilai-nilai yang ia percaya dan juga rekomendasi konsumen lainnya yang telah berbagi (Dehghani and Tumer 2015).

\section{Kerangka Pemikiran Teoritis dan Perumusan Hipotesis Keputusan Pembelian dan Nilai hadiah}

Pengalaman yang telah terbentuk pada konsumen akan memudahkan konsumen dalam menentukan produk mana yang memiliki nilai hadiah yang lebih tinggi dibanding produk yang sejenis, semakin baik pengalaman konsumen dalam menggunakan produk maka semakin kuat akan persepsi nilai hadiah yang dirasakan pada produk sehingga konsumen akan merasa bahwa produk memang layak untuk dijadikan sebagai barang hadiah untuk orang yang diinginkan.

Hal Ini sesuai dengan penelitian yang dilakukan oleh Chen (2012) yang mengatakan bahwa pengalaman yang telah terbentuk secara positif pada sebuah produk akan membuat ia semakin yakin bahwa produk memiliki nilai hadiah yang kuat untuk diberikan kepada penerima.dan Kim and Littrell (2001) bahwa pemberi hadiah menggunakan persepsinya terhadap suatu produk yang diinginkannya sebagai pertimbangan dalam menentukan souvenir (produk) mana yang cocok untuk diberikan pada orang yang dituju.

H1: Pengalaman Wisatawan berpengaruh positif terhadap Nilai Hadiah

\section{Pengalaman Wisatawan dan Nilai Nostalgia}

Pengalaman yang terbentuk pada konsumen dari berbagai tahapan (pencarian, pembelian, penggunaan, fase setelah pemakaian) akan menjadi penting apabila pengalaman yang tercipta memiliki nilai yang positif bagi diri konsumen, dengan bagitu maka akan terbentuk keterikatan yang kuat antara konsumen dengan produk atau tempat tersebut. Adanya pengalaman positif yang kuat maka akan menciptakan ingatan kuat pada dirinya, sehingga ketika ia mencoba sebuah produk yang sama maka terlintas kembali kenangan masa lalunya.

Hal ini sesuai dengan penelitian Manthiou, Lee et al. (2014), yang mengatakan bahwa dimensi-dimensi yang terbentuk dari pengalaman konsumen selama ia mengkomsumsi suatu produk secara positif terkait dengan kejelasan 
kenangan yang telah ada, dengan kata lain semakin kuat pengalaman yang ada pada diri konsumen, maka akan semakin kuat ingatan masa lalu yang tergambar oleh konsumen.

H2: Pengalaman wisatawan berpengaruh positif terhadap nillai nostalgia

\section{Pengalaman Wisatawan dan Nilai Ikonik}

Dalam menentukan mana makanan yang menjadi ikonik suatu daerah kebanyakan dari wisatawan akan menentukan pilihannya tersebut melalui isyarat visual baik pada keaslian produk, maupun isyarat berupa symbol, tulisan yang membawa keyakinan makanan tersebut adalah asli Semarang (Beverland and Farrelly 2010).

Semakin banyaknya pengalaman seseorang didalam mencoba berbagai produk, maka akan mengetahui mana produk yang mampu mewakili gambaran dari daerah yang dikunjungi dan memberikan kesan asli dari daerah tersebut, dalam menentukan produk mana yang menurutnya adalah ikon dari suatu daerah biasanya dilihat dari seberapa mampunya atribut-atribut yang ada pada produk mampu menggambarkan ke aslian dan budaya suatu daerah (Grayson and Martinec 2004, Liu, Yannopoulou et al. 2015).

H3: Pengalaman Wisatawan berpengaruh positif terhadap Nilai Ikonik

\section{Nilai Ikonik dan Nilai Hadiah}

Sebuah produk dikatakan memiliki nilai ikonik yang kuat dimata konsumen apabila konsumen dapat melihat produk tersebut memiliki hubungan yang kuat dengan budaya lokalnya, baik itu diaplikasikan dalam bentuk simbol pada kemasan, tema makanan, bentuk maupun warna. Konsumen yang mengkonsumsi ulang produk lokal yang memiliki nilai ikonik akan lebih mudah merasakan sensasi kembali ke masa lalu (nostalgia). Hal ini sesuai dengan penelitian yang pernah dilakukan oleh Orth and Gal (2014) yang menyatakan bahwa semakin kuat nilai ikonik yang konsumen rasakan pada suatu produk maka semakin kuat tingkat nostalgia yang ia rasakan ketika mengkonsumsi produk tersebut.

H4: Nilai Ikonik berpengaruh positif terhadap nilai nostalgia

\section{Nilai Hadiah dan Keputusan Pembelian}

Pada saat memilih barang yang dijadikan sebagai hadiah, pemberi hadiah akan melakukan evaluasi terhadap barang yang akan dibeli, wisatawan biasanya memilih barang yang mudah untuk dibawa pulang dan produk lokal yang orisinis sebagai souvenir, menurut Kim \& Littrell (2001) wisatawan dalam menentukan produk yang akan dibeli sebagai hadiah maka atribut yang dilihat adalah, kemudahan untuk dibawa, bentuk souvenir, produk merupakan buatan lokal. 
Dengan kata lain semakin kuat nilai hadiah yang dirasakan maka konsumen akan semakin kuat keputusannya untuk membeli barang tersebut sebagai souvenir untuk orang yang ia inginkan.

H5: Nilai Hadiah berpengaruh positif terhadap Keputusan Pembelian

\section{Nilai Nostalgia dan Keputusan Pembelian}

Nilai nostalgia pada produk dapat dibentuk dengan memberikan sentuhan masa lalu pada produk baik melalui aroma, sentuhan, irama atau gambar. Dengan memberikan nilai nostalgia pada produk maka konsumen akan tertarik untuk mencoba kembali dan merasakan kenangan dari produk yang tersedia.

Dalam penelitian Marchegiani \& Phau (2010) menemukan bahwa sikap dan niat membeli terhadap produk yang memiliki nilai nostalgia meningkat secara signifikan dengan setiap peningkatan nilai nostalgia yang dialami oleh konsumen, dan didalam penelitian llyoung, et al, (2016) produk yang mengandung pesan nostalgia mampu meningkatkan sikap merek, dan niat membeli yang lebih kuat yang langsung menyebabkan tingginya keputusan pembelian.

H6: Nilai Nostalgia berpengaruh postif terhadap Keputusan Pembelian

\section{Nilai Ikonik dan Keputusan Pembelian}

Wisatawan dalam memilih produk untuk dikonsumsi sendiri maupun sebagai souvenir yang akan dibawa pulang maka akan lebih memprioritaskan produk yang memiliki atribut-atribut lokal baik dalam bentuk bentuk symbol, merek, ataupun tema pada ingatan masyarakat, semakin kuat nilai ikonik yang dirasakan oleh wisatawan maka akan semakin meningkatkan niatnya untuk membeli produk tersebut.

Pada penelitian Pearce, Wu et al. (2015) diketahui bahwa produk yang memiliki nilai ikonik dan dapat diaplikasikan secara visual mampu untuk meningkatkan daya tarik konsumen untuk membeli atau menggunakan produknya. Produk yang mampu menampilkan nilai ikonik daerahnya kepada konsumen akan mampu memberikan gambaran bahwa produk tersebut adalah produk lokal dan asli daerah tersebut, sehingga konsumen akan tertarik untuk membeli. H7: Nilai Ikonik berpengaruh positif terhadap Keputusan Pembelian.

Dari hasil penjabaran telaah pustaka dan hipotesis yang diajukan pada penelitian, maka dibentuk kerangka teoritis dari penelitian. Adapun kerangka penelitian yang disajikan pada Gambar 1 : 


\section{Gambar 1}

\section{Kerangka Penelitian}

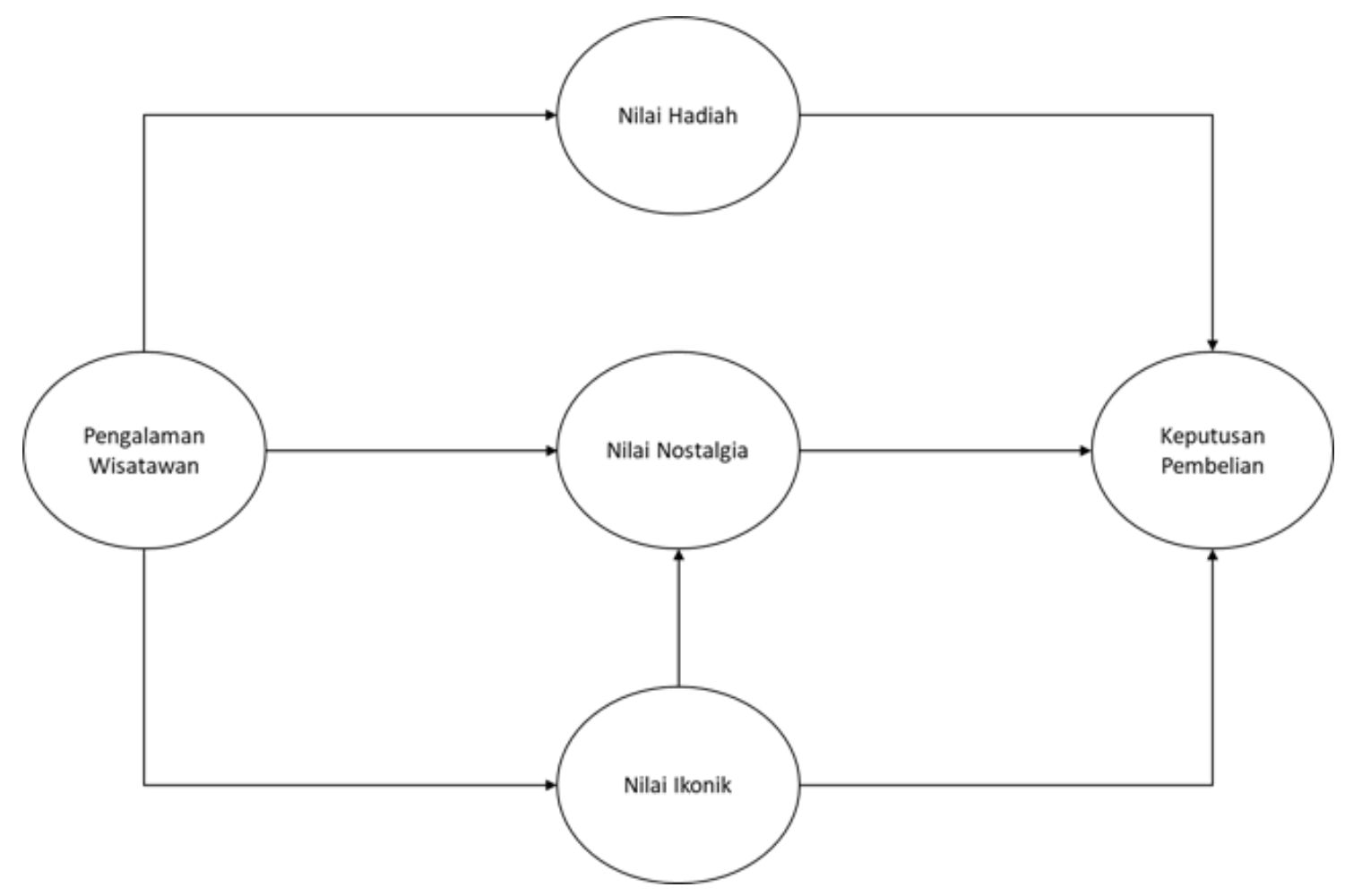

\section{METODE PENELITIAN}

Variable ekdogen pada penelitian ini adalah pengalaman wisatawan (X1) yang didefinisikan oleh indikator perasaan bahagia (1), menikmati pengalaman (2), perasaan tenggelam (3), merasa senang (4), pengalaman menyenangkan (5). Variable endogen pada penelitian ini adalah nilai hadiah (X2) yang didefinisikan oleh indikator seberapa penting penerima (1), seberapa dekat penerima (2), status penerima (3), nilai nostalgia (X3) didefinisikan oleh indikator membuat bernostalgia (1), membangkitkan kenangan indah (2), mengingat masa indah (3), pengingat menyenangkan (4), nilai ikonik (X4) didefinisikan oleh indikator sudah ada dari dulu (1), menggunakan resep masa lalu (2), sering disebut dalam dokumen (3), sesuai yang dipikirkan (4) dan keputusan pembelian (X5) yang didefinisikan oleh indikator bermaksud membeli (1), berencana untuk membeli (2), membeli dikemudian hari (3).

Pada penelitian ini yang menjadi populasi yaitu wisatawan yang berkunjung ulang dan membeli makanan lokal kota Semarang, teknik yang digunakan untuk mengambil sampel yaitu purposive sampling dengan sampel penelitian yang diambil sebanyak 160 responden. Penelitian menggunakan data primer maupun skunder, data primer penelitian diperoleh dari kuesioner yang dibagikan langsung 
kepada calon responden dengan indeks tiap jawaban dari item pertanyaan adalah 1 sampai 10 dimana 1 sangat tidak setuju (STS) dan 10 sangat setuju (SS) dan data sekunder penelitian berdasarkan data yang dikumpulkan dari artikel, jurnal maupun majalah yang digunakan untuk menguatkan penelitian yang akan dilakukan. Metode yang digunakan untuk menganalisis data penelitian adalah structural equation model (SEM) yang terdiri dari 7 tahap yang dijalankan dengan program AMOS 24.0. sebelum melakukan analisis terhadap hipotesis yang telah dibangun, data terlebih dahulu dinilai agar model dianggap sesuai atau overall fit model sehingga data dapat diketahui apakah mampu mewakilkan tiap variable yang ingin diteliti.

\section{HASIL PENELITIAN DAN PEMBAHASAN}

\section{Analisis Full Model dengan Structural Equation Model}

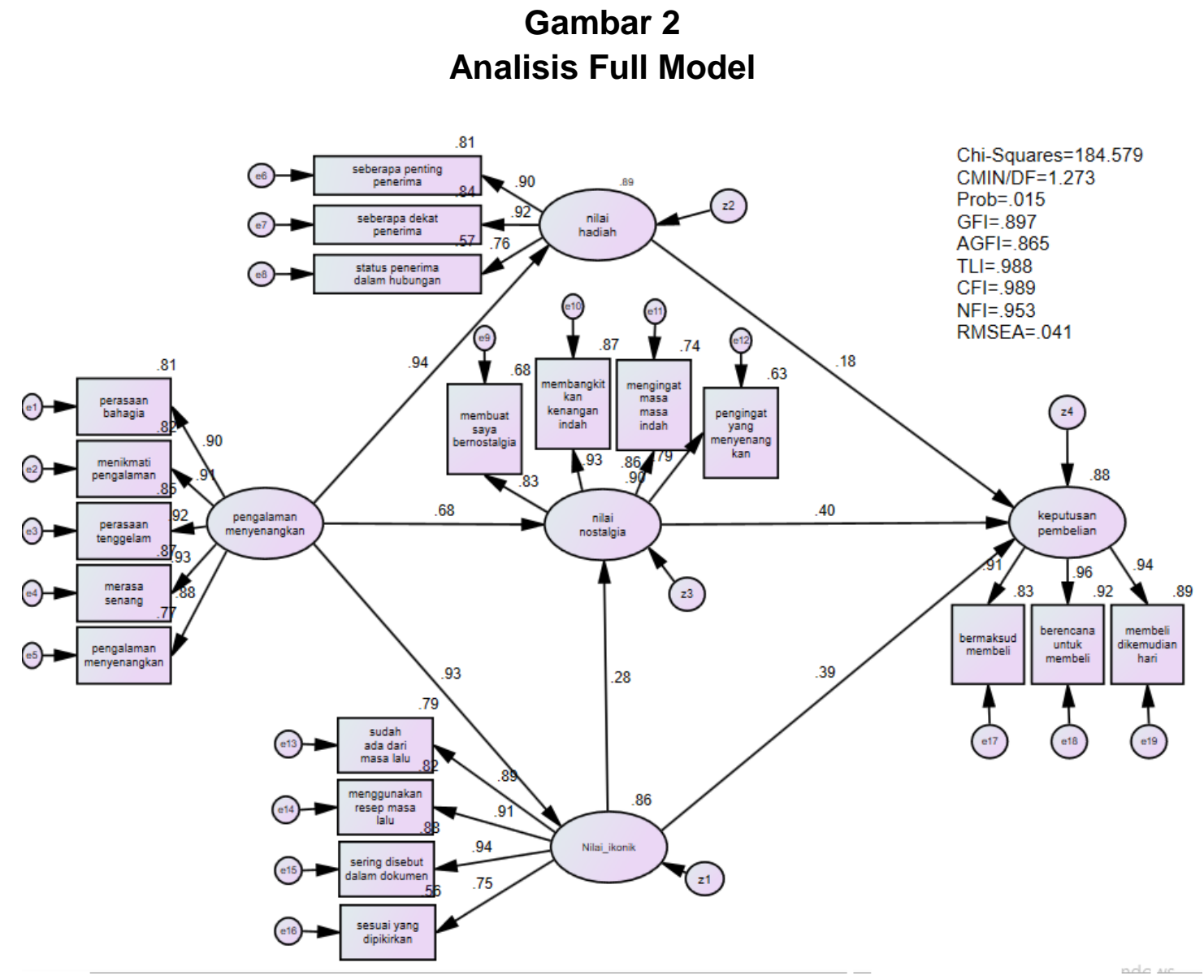


Tabel 1

Hasil Analisis Full Model

\begin{tabular}{cccc}
\hline Kriteria & Cut of Value & Hasil & Evaluasi \\
\hline Chi-Square & $X^{2}$ with df $145, \mathrm{P}: 5 \%$ is124.34 & 184.579 & Baik \\
Probability & $\geq 0.05$ & .015 & Baik \\
GFI & $\geq 0.90$ & .897 & Marginal \\
AGFI & $\geq 0.90$ & .865 & Marginal \\
TLI & $\geq 0.95$ & .988 & Baik \\
CFI & $\geq 0.95$ & .989 & Baik \\
CMIN/DF & $\leq 2.00$ & 1.273 & Baik \\
RMSEA & $\leq 0.80$ & .041 & Baik \\
\hline
\end{tabular}

Dari tabel diatas dapat dilihat pada pengujian full model nilai dari chi-quare pada model yakni 184.579 , memenuhi syarat karena lebih dari syarat minimum yakni df 145, P: $5 \%$ adalah 124.34 dan nilai probabilitas .015 memenuhi syarat dari kriteria yang ditentukan yakni Probability $\geq 0.05$. Pada nilai TLI diperoleh hasil 0.988 yang artinya telah memenuhi hasil kriteria yang ditentukan yakni $\geq 0.95$, nilai CFI yang diperoleh adalah 0.989 telah memenuhi syarat dengan kriteria $\mathrm{CFI} \geq 0.95$, dan CMIN/DF diperoleh nilai 1.273 memenuhi kriteria yang telah ditentukan yakni $\geq 2.00$. hal ini menunjukkan bahwa model dianggap baik (diterima).

\section{Tabel 2}

Hasil Regression Weight Analisis SEM

\begin{tabular}{lcccc}
\hline & Estimate & S.E. & C.R. & P \\
\hline Pengalaman wisatawan $\rightarrow$ Nilai lkonik & 0.762 & 0.068 & 11.236 & ${ }^{* * *}$ \\
Pengalaman wisatawan $\rightarrow$ Nilai Nostalgia & 0.631 & 0.119 & 5.282 & ${ }^{* * *}$ \\
Pengalaman wisatawan $\rightarrow$ Nilai hadiah & 0.686 & 0.059 & 11.563 & ${ }^{* * *}$ \\
Nilai ikonik $\rightarrow$ nilai notalgia & 0.321 & 0.141 & 2.282 & 0.023 \\
Nilai hadiah $\rightarrow$ keputusan pembelian & 0.314 & 0.179 & 1.756 & 0.079 \\
Nilai ikonik $\rightarrow$ keputusan pembelian & 0.618 & 0.186 & 3.322 & ${ }^{* * *}$ \\
Nilai nostalgia $\rightarrow$ keputusan pembelian & 0.564 & 0.178 & 3.164 & 0.002 \\
\hline
\end{tabular}

Pengujian dari ketujuh hipotesis yang ingin diuji pada penelitian ini dapat dilakukan dengan menganilisis critical ratio $(\mathrm{CR})$ yang dihasilkan dan pobabilitas dari hubungan kausalitas hipotesis diterima apabila nilai dari probabilitas $<0.05$. Hubungan antara Pengalaman wisatawan terhadap Nilai hadiah menunjukkan CR sebesar 11.236 dengan probailitas 0.000 . hal ini menunjukkan bahwa pengalaman wisatawan terbukti secara signifikan berpengaruh terhadap nilai hadiah. Hubungan antara pengalaman wisatawan terhadap nilai nostalgia menunjukkan CR sebesar 5.282 dengan probabilitas 0.000 , hal ini menunjukkan bahwa pengalaman wisatawan terbukti secara signifikan berpengaruh terhadap nilai nostalgia. Hubungan antara pengalaman wisatawan terhadap nilai ikonik menunjukkan CR 
sebesar 11.563 dengan probabilitas 0.000 , hal ini menunjukkan bahwa pengalaman wisatawan terbukti secara signifikan berpengaruh terhadap nilai ikonik. hubungan nilai hadiah dengan keputusan pembelian menunjukkan CR sebesar 1.756 dengan probabilitas 0.079 , hal ini menunjukkan bahwa nilai hadiah tidak berpengaruh terhadap keputusan pembelian. Hubungan nilai ikonik dengan nilai nostalgia menunjukkan CR sebesar 2.282 dengan probabilitas 0.023 , hal ini menunjukkan nilai ikonik berpengaruh secara signifikan terhadap nilai nostalgia. Hubungan nilai nostalgia terhadap keputusan pembelian menunjukkan CR sebesar 3.322 dengan probabilitas 0.000 , hal ini menunjukkan bahwa nilai nostalgia berpengaruh secara signifikan terhadap keputusan pembelian. Hubungan nilai ikonik terhadap keputusan pembelian menunjukkan CR sebesar 3.164 dengan probabilitas 0.002 , hal ini menunjukkan bahwa nilai nostalgia berpengaruh secara signifikan terhadap keputusan pembelian.

\section{KESIMPULAN DAN IMPLIKASI}

\section{Hasil Uji Hipotesis 1}

Hipotesis 1: pengalaman wisatawan berpengaruh positif terhadap nilai hadiah

Hasil analisis yang dilakukan menunjukkan bahwa ada pengaruh signifikan antara pengalaman wisatawan terhadap nilai hadiah pada pembelian makanan lokal kota Semarang. Artinya terjadi persepsi nilai hadiah dibenak konsumen pada produk makanan kota Semarang dengan seiring bertambahnya pengalaman wisatawan dalam mengkonsumsi makanan lokal.

\section{Hasil Uji Hipotesis 2}

Hipotesis 2: pengalaman wisatwaan berpengaruh terhadap nilai nostalgia

Hasil analisis yang dilakukan menunjukkan bahwa ada pengaruh signifikan antara pengalaman wisatawan terhadap nilai nostalgia pada pembelian makanan lokal kota Semarang. Artinya terjadi persepsi nostalgia yang dirasakan oleh wisatawan ketika melihat makanan lokal kota Semarang seiring dengan bertambahnya pengalaman wisatawan pada makanan lokal

\section{Hasil Uji Hipotesis 3}

Hipotesis 3: pengalaman wisatawan berpengaruh positif terhadap nilai ikonik

Hasil analisis yang dilakukan menunjukkan bahwa ada pengaruh signifikan antara pengalaman wisatawan terhadap nilai ikonik pada pembelian makanan lokal kota Semarang. Artinya semakin banyak pengalaman wisatawan maka 
semakin kuat persepsinya bahwa produk makanan lokal tersebut merupakan ikoniknya kota Semarang.

\section{Hasil Uji Hipotesis 4}

Hipotesis 4: nilai ikonik berpengaruh positif terhadap nilai nostalgia

Hasil analisis yang dilakukan menunjukkan bahwa ada pengaruh signifikan antara nilai ikonik terhadap nilai nostalgia pada makanan lokal kota Semarang. Artinya semakin ikonik produk makanan Semarang maka semakin mudah bagi wisatwan untuk cepat merasakan persepsi nostalgianya ketika mengkonsumsi makanan lokal kota Semarang.

\section{Hasil Uji Hipotesis 5}

Hipotesis 5: nilai hadiah tidak berpengaruh terhadap keputusan pembelian

Hasil analisis menunjukkan bahwa tidak terdapat pengaruh nilai hadiah yang dirasakan terhadap keputusan untuk membeli makanan lokal sebagai souvenir. Artinya wisatawan tidak merasakan bahwa makanan lokal layak untuk diberikan sebagai oleh-oleh kepada orang penting bagi dirinya.

\section{Hasil Uji Hipotesis 6}

Hipotesis 6: nilai nostalgia berpengaruh positif terhadap keputusan pembelian

Hasil analisis menunjukkan bahwa terdapat pengaruh signifikan antara nilai nostalgia yang dirasakan terhadap keputusan pembelian makanan lokal kota Semarang. Artinya semakin kuat nostalgia yang dirasakan oleh wisatawan terhadap makanan lokal maka semakin kuat keinginannya untuk membeli makanan tersebut.

\section{Hasil Uji Hiptesis 7}

Hipotesis 7: nilai ikonik berpengaruh positif terhadap keputusan pembelian

Hasil analisis menunjukkan bahwa terdapat pengaruh signifikan antara nilai ikonik yang dirasakan terhadap keputusan pembelian makanan lokal kota Semarang. Artinya semakin kuat persepsi bahwa makanan tersebuat merupakan ikoniknya kota Semarang maka semakin kuat keinginan untuk membeli makanan lokal kota Semarang.

Penelitian ini ditujukan untuk menjawab permasalah tentang bagaimana menjawab permasalah pengalaman wisatawan terhadap keputusan pembelian makanan local kota semarang. Untuk menjawab hal tersbut maka dari analisis yang telah dilakukan terdapat 3 proses untuk meningkatkan keputusan wisatawan dalam pembelian makanan lokal Kota Semarang. 
Gambar 3. Proses Peningkatan 1

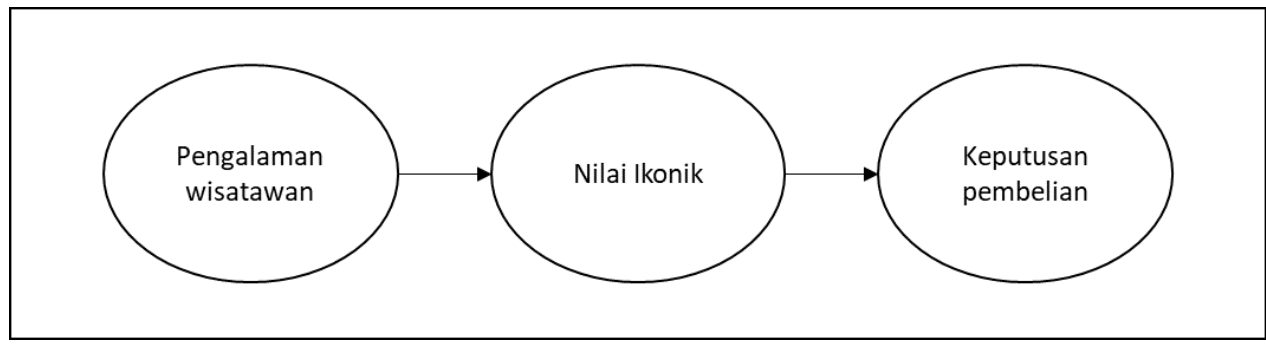

Pengalaman wisatawan yang terbentuk secara positif terhadap makanan lokal kota Semarang yang di ungkap respond dengan cara mereka merasa bahagia ketika mengkonsumsi makanan lokal Semarang, dan merasa ada yang kurang bila ke Semarang tapi tidak membeli dan mengkonsumsi makanan kota Semarang dan adanya perasaan puas pada liburan mereka ketika kegiatan liburan mereka diisi dengan membeli dan mengkonsumsi makanan lokal semaran, maka akan terbentuk persepsi bahwa makanan tersebut memang khas Semarang. Perasaan itu semakin kuat dengan adanya berbagai dokumen yang mengulas tentang makanan khas Semarang, dengan semakin kuatnya perasaan bahwa makanan lokal tersebut memang ikoniknya kota Semarang maka akan membuat wisatawan memiliki niat yang kuat untuk membeli makanan lokal kota Semarang, yang diungkap melalui niatnya membeli makanan lokal kota Semarang ketika berwisata diSemarang, berencana membeli baik ketika sedang berada diSemarang atau ketika akan meninggalkan kota Semarang.

\section{Gambar 4. Proses peningkatan 2}

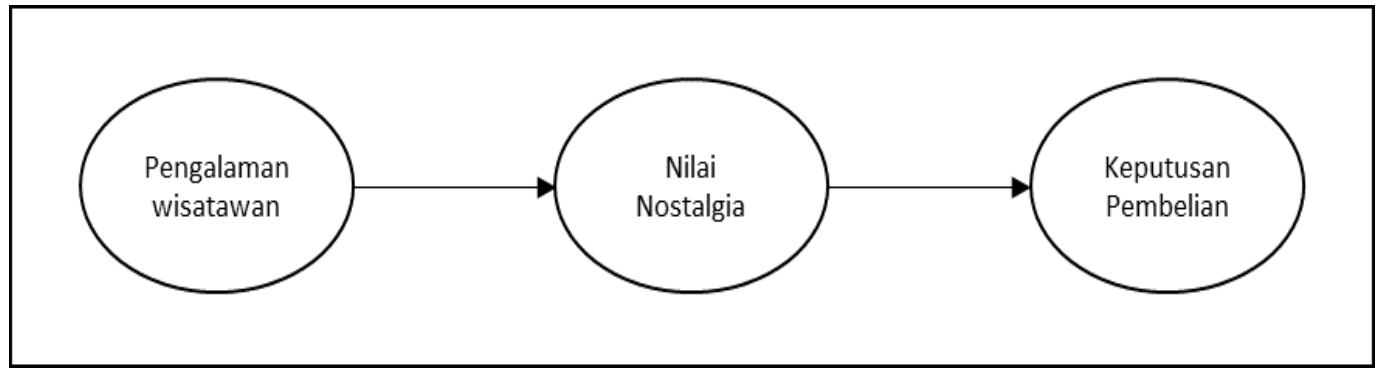

Nilai nostalgia yang positif terbangun dari pengalaman wisatan yang positif terhadap makanan lokal kota Semarang. Hal ini diungkap responden dengan merasa kembali ke masa masa menyenangkan dimasa lalu dikarenakan rasa khas dan bentuk yang tidak berubah dari dahulu. Mengingat perasaan bahagia ketika mengkonsumsi makanan lokal Semarang. Perasaan nostalgia semakin kuat ketika mengkonsumsi bersama orang yang sebelumnya makan bersama dia. Semakin 
kuat perasaan nostalgia yang dirasakan wisatawan terhadap makanan lokal kota Semarang maka semakin kuat pula keinginannya untuk membeli makanan tersebut. Hal ini diungkapkan responden dengan cara berniat membeli makanan lokal Semarang ketika sedang berwisata di kota Semarang.

\section{Gambar 5. Proses peningkatan 3}

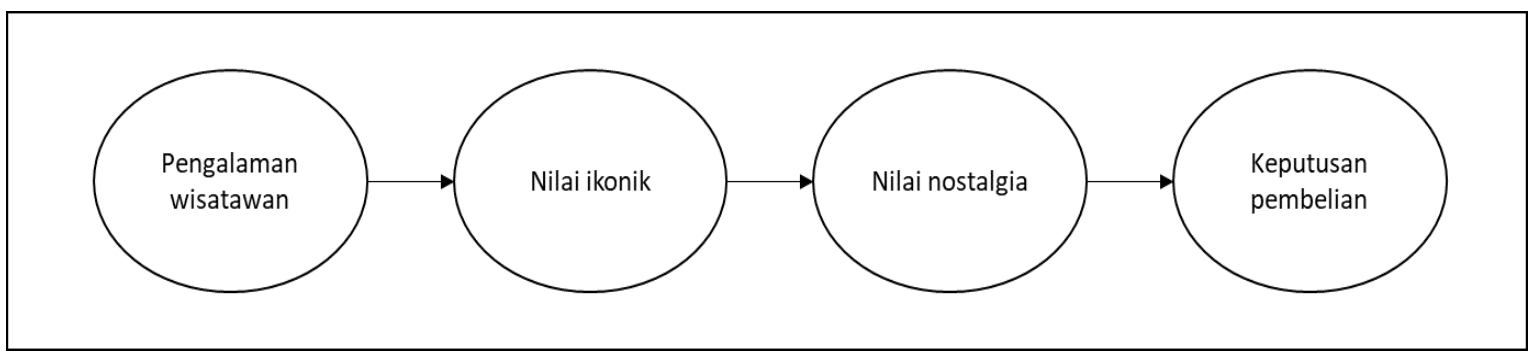

Melalui pendekatan analisis teori penciptaan nilai, pengalaman konsumen dibentuk selama wisatawan mencoba berbagai makanan lokal Semarang. Semakin banyak pengalaman positif terhadap makanan Semarang maka akan membentuk persepsi yang kuat bahwa makanan tersebut memang milik Semarang dan menjadi ikoniknya dari Semarang. Semakin percaya maka ia akan semakin merasa bahagia ketika mengkonsumsi makanan lokal Semarang. Wisatawan akan merasa ada yang kurang apabila mereka berwisata tapi tidak mencicipi makanan khas Semarang. Hasil persepi yang kuat tersebut diperoleh oleh wisatawan karena mereka selalu menjumpai makanan lokal kota Semarang yang tidak berubah baik tampilan dan juga rasa, serta ketika namanya disebut banyak orang yang mengetahui makanan itu adalah khas Semarang dan didukung adanya catatan di berbagai dokumen tentang makanan khas kota Semarang. Hasil dari pengalaman tersebut membentuk kenangan yang menyenangkan pada diri wisatawan terhadap makanan lokal Semarang. Hal ini diungkapkan dengan merasa kembali mengingat masa menyenangkan dimasa lalu, mengingat kembali perasaan bahagia. Sehingga terbentuk niat untuk mengambil keputusan pembelian makanan lokal Semarang. Hal ini diungkap responden melalui pasti akan membeli makanan lokal Semarang, berencara untuk membeli sewaktu berada di Semarang dan berencana akan membeli ketika meninggalkan kota Semarang.

\section{REFERENSI}

Agata Wawrzyniak, A. W., et al. (2012). "An Empirical Study of the Factors Influencing Consumer Behaviour in the Electric Appliances Market." Contemporary Economics 6(3): 76. 
Bahri, S. and F. Zamzam (2012). Model Penelitian Kuantitatif Berbasis SEM-Amos. Yogyakarta, Cv Budi Utama.

Beverland and F. J. Farrelly (2010). "The Quest for Authenticity in Consumption: Consumers' Purposive Choice of Authentic Cues to Shape Experienced Outcomes." Journal of Consumer Research 36(5): 838-856.

Bronner, F. and R. de Hoog (2014). "Social media and consumer choice." International Journal of Market Research 56(1): 51-71.

Chen, D.-J. (2012). "Global concept, lokal practice: Taiwanese experience of CouchSurfing." Hospitality \& Society 1(3): 279-297.

Cui, R. (2015). "A Review of Nostalgic Marketing." Journal of Service Science and Management 08(01): 125-131.

Dehghani, M. and M. Tumer (2015). "A research on effectiveness of Facebook advertising on enhancing purchase intention of consumers." Computers in Human Behavior 49: 597-600.

Dodd, T. H., et al. (2016). "Differential Effects of Experience, Subjective Knowledge, and Objective Knowledge on Sources of Information used in Consumer Wine Purchasing." Journal of Hospitality \& Tourism Research 29(1): 3-19.

Ferdinand, A. (2014). Metode Penelitian Manajemen Pedoman Penelitian untuk Menulis Skripsi, Tesis, dan Disertasi Ilmu Manajemen. Semarang, BP UNDIP.

Ferdinand, A. T. (2014). Metode Penelitian Manajemen Pedoman Penelitian Untuk Penulisan Skripsi Tesis Dan Disertasi Ilmu Manajemen. Semarang, Indonesia, Badan Penerbit Universitas Diponegoro.

Ferdinand, A. T. and L. K. Fitriani (2015). "Acculturative Iconic Product Attractiveness and Marketing Performance." Journal of Global Strategic Management 2(9): 15-15.

Frambach, R. t., et al. (2007). "The Impact Of Consumer Internet Experience On Channel Preference And Usage Intentions Across The Different Stages Of The Buying Process." Journal of Interactive Marketing 21(2): 26-41.

Gao, H., et al. (2017). "The influence of face on Chinese tourists' gift purchase behaviour: The moderating role of the gift giver-receiver relationship." Tourism Management 62: 97-106.

Grayson, K. and R. Martinec (2004). "Consumer Perceptions of Iconicity and Indexicality and Their Influence on Assessments of Authentic Market Offerings." Journal of Consumer Research 33.

Holak, S. L. (2013). "From Brighton beach to blogs: exploring food-related nostalgia in the Russian diaspora." Consumption Markets \& Culture 17(2): 185-207. 
Hultén, B., et al. (2015). Sensory Marketing. United States, Palgrave Macmillan.

Ju, I., et al. (2016). "Nostalgic marketing, perceived self-continuity, and consumer decisions." Management Decision 54(8): 2063-2083.

Karimi, S., et al. (2015). "The effect of prior knowledge and decision-making style on the online purchase decision-making process: A typology of consumer shopping behaviour." Decision Support Systems 77: 137-147.

Kim, H.-W., et al. (2011). "Investigating the intention to purchase digital items in social networking communities: A customer value perspective." Information \& Management 48(6): 228-234.

Kim, S. and M. A. Littrell (2001). "Souvenir Buying Intentions For Self Versus Others." Annals of Tourism Research 28(3): 638-657.

Kravets, O. and Ö. Örge (2010). "Iconic Brands." Journal of Material Culture 15(2): 205-232.

Kwek, A. and Y.-S. Lee (2010). "Chinese Tourists and Confucianism." Asia Pacific Journal of Tourism Research 15(2): 129-141.

Kwortnik, R. J. and W. T. Ross (2007). "The role of positive emotions in experiential decisions." International Journal of Research in Marketing 24(4): 324-335.

Manthiou, A., et al. (2014). "The experience economy approach to festival marketing: vivid memory and attendee loyalty." Journal of Services Marketing 28(1): 22-35.

Mohd Noor, M. N., et al. (2016). "Understanding Consumers and Green Product Purchase Decision in Malaysia: A Structural Equation Modeling - Partial Least Square (SEM-PLS) Approach." Asian Social Science 12(9): 51.

Orth, U. R. and A. Bourrain (2008). "The influence of nostalgic memories on consumer exploratory tendencies: Echoes from scents past." Journal of Retailing and Consumer Services 15(4): 277-287.

Orth, U. R. and S. Gal (2014). "Persuasive Mechanisms of Nostalgic Brand Packages." Applied Cognitive Psychology 28(2): 161-173.

Srivastava, M. and D. Kaul (2016). "Exploring the link between customer experience-loyalty-consumer spend." Journal of Retailing and Consumer Services 31: 277-286.

Steinmetz, R. (2010). Food, Tourism and Destination Differentiation: The Case of Rotorua, New Zealand. School of Hospitality and Tourism, AUT University.

Hart, B., et al. (2016). "Predictors of purchase intention of luxury South Sea pearls." Australasian Marketing Journal (AMJ) 24(4): 344-350. 
Teixeira, J., et al. (2012). "Customer experience modeling: from customer experience to service design." Journal of Service Management 23(3): 362376.

Triantafillidou, A. and G. Siomkos (2014). "Consumption experience outcomes: satisfaction, nostalgia intensity, word-of-mouth communication and behavioural intentions." Journal of Consumer Marketing 31(6/7): 526-540.

Wu, C.-S. (2015). "A STUDY ON CONSUMERS' ATTITUDE TOWARDS BRAND IMAGE, ATHLETES' ENDORSEMENT, AND PURCHASE INTENTION." The International Journal of Organizational Innovation 8: 233-253.

Yang, Z.-Y. and L.-Y. He (2011). "Goal, customer experience and purchase intention in a retail context in China: An empirical study." African Journal of Business Management 5(16): 6738-6746.

Yeh, S.-S., et al. (2012). "Nostalgic Emotion, Experiential Value, Destination Image, and Place Attachment of Cultural Tourists." Advances in Hospitality and Leisure: 167-187.

Zhang, Y. and N. Epley (2011). "How Surprisingly Little Thoughts Count in GiftGiving: on Receiver'S Motivated Appreciation For Giver'S Thoughts." Advances in Consumer Research 39: S213-S214.

Zhang, Y. and N. Epley (2011). "How Surprisingly Little Thoughts Count in GiftGiving: on Receiver'S Motivated Appreciation For Giver'S Thoughts." Association For Consumer Research 39: 213-214. 